\title{
Antenatal Administration of Betamethasone Contributes to Intimal Thickening of the Ductus Arteriosus
}

\author{
Takahiro Kemmotsu, Utako Yokoyama, Junichi Saito, \\ Satoko Ito, Azusa Uozumi, Shiho Iwasaki, \\ Shigeru Nishimaki, Shuichi Ito, Munetaka Masuda, \\ Toshihide Asou, and Yoshihiro Ishikawa
}

\section{Keywords}

Ductus arteriosus $\cdot$ Glucocorticoid $\cdot$ Intimal thickening

Antenatal betamethasone (BTM) is a standard therapy to reduce respiratory distress syndrome [1], and some reports indicate that BTM decreases prevalence of patent ductus arteriosus in preterm infants [2]. Closure of the ductus arteriosus (DA) requires morphological remodeling, i.e., intimal thickening (IT) formation [3]. However, the role of BTM in IT formation of the preterm DA has not been reported.

\footnotetext{
T. Kemmotsu

Department of Pediatrics, Yokohama City University, Yokohama, Japan

Cardiovascular Research Institute, Yokohama City University, Yokohama, Japan

U. Yokoyama $(\triangle) \cdot J$. Saito $\cdot$ S. Ito $\cdot$ Y. Ishikawa

Cardiovascular Research Institute, Yokohama City University, Yokohama, Japan e-mail: utako@yokohama-cu.ac.jp; yishikaw@med.yokohama-cu.ac.jp
}

A. Uozumi · S. Nishimaki $\cdot$ S. Ito

Department of Pediatrics, Yokohama City University, Yokohama, Japan

S. Iwasaki

Perinatal Center, Yokohama City University Medical Center, Yokohama, Japan

M. Masuda

Department of Surgery, Yokohama City University, Yokohama, Japan

T. Asou

Department of Cardiovascular Surgery, Kanagawa Children's Medical Center,

Yokohama, Japan 
First, we analyzed the expression of glucocorticoid receptor (GR) in preterm and term DA tissues. Quantitative RT-PCR of rat DA tissues (day 19 and day 21 of gestation) and immunohistochemistry of the human DA tissue (day 7, coarctation of the aorta) showed that GR was highly expressed in the human and rat DAs. We then performed DNA microarray analysis using smooth muscle cells of preterm rat DA (DASMCs) on day 20 of gestation stimulated with or without BTM. Among all of the genes detected in preterm DASMCs, the gene $\mathrm{X}$ was markedly increased by BTM stimulation, which was confirmed by quantitative RT-PCR in rat preterm DASMCs, but not in preterm rat aortic smooth muscle cells. A scratch assay demonstrated that BTM promoted preterm DASMC migration, which was attenuated by the gene X-targeted siRNA.

Furthermore, we examined whether BTM increased IT formation in vivo. Maternal rats were administered intravenously with BTM or normal saline (control) on day 18 and 19 of gestation, and fetal rat DA tissues were obtained on day 20 of gestation. The ratio of IT to tunica media was significantly higher in BTM treatment group $(n=5, p<0.05)$.

In conclusion, these data suggest that antenatal BTM administration promotes IT of the DA through the gene $\mathrm{X}$-mediated DASMC migration.

Acknowledgment This study was funded by MEXT/JSPS KAKENHI (S.I., 43008732; U.Y., 16H05358, 15H05761; J.S., 16H07107; Y.I., H1605300, 16K15205), Yokohama Foundation for Advancement of Medical Science (J.S.), and AMED (Y.I., 66890011, 66890023, 17ek0109240h0001, A261TS).

\section{References}

1. Roberts D, et al. Antenatal corticosteroids for accelerating fetal lung maturation for women at risk of preterm birth. Cochrane Datebase Syst Rev. 2006;19(3):CD004454.

2. Been JV, et al. Antenatal steroids and neonatal outcome after chorioamnionitis: a meta-analysis. BJOG. 2011;118(2):113-22.

3. Yokoyama $\mathrm{U}$, et al. Regulation of vascular tone and remodeling of the ductus arteriosus. $\mathbf{J}$ Smooth Muscle Res. 2010;46(2):77-87.

Open Access This chapter is licensed under the terms of the Creative Commons Attribution 4.0 International License (http://creativecommons.org/licenses/by/4.0/), which permits use, sharing, adaptation, distribution and reproduction in any medium or format, as long as you give appropriate credit to the original author(s) and the source, provide a link to the Creative Commons license and indicate if changes were made.

The images or other third party material in this chapter are included in the chapter's Creative Commons license, unless indicated otherwise in a credit line to the material. If material is not included in the chapter's Creative Commons license and your intended use is not permitted by statutory regulation or exceeds the permitted use, you will need to obtain permission directly from the copyright holder.

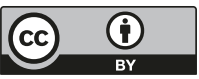

